\title{
Design and Implementation of Concrete Thermal Storage Stove
}

\author{
Gyang Davou Chung, Pahalson C. A. D, Jennifer Kadala
}

\begin{abstract}
Cooking has been an important part of mankind civilization. Several means of providing controlled heat for cooking had been developed in the past. However, as civilization grows, the use of refine fossil fuel and electric stoves became the dominant means of providing heat for cooking. The cost of refine fossil fuel had regularly fluctuated and generally increases on average. In some locations in the world, the time for supply of electricity and the duration of it availability is unpredictable. Also, the cost of electricity varies between the day and the night in some countries. These problems led to the development of a thermal storage stove. The stove use electric heating elements for direct cooking and charging the thermal energy storage unit. The stored heat energy will be use at any time of the day. The stove with a theoretically estimated heat energy storage capacity of 2.7 MJ was constructed. And from measurements, the device was found to be more effective in the first 10 hours when charged to a device dependent temperature factor of about $82{ }^{\circ} \mathrm{C}$.
\end{abstract}

Keywords: Electric, Stove, Cooking, Thermal, Storage

\section{INTRODUCTION}

An electric stove is a device with an integrated electrical heating element to cook. Electric stoves became popular as replacements for solid-fuel (wood or coal) stoves which emit pollution in the environment and required more labor to operate and maintain [1]. Concurrently, gas stove with high potential for fire outbreak was also in development. The Electric stoves in use have followed a series of technological advancement in their development. The first technology used resistive heating coils which heated iron hotplates, on top of which the pots were placed. It was subsequently developed into a spiral hollow steel tube that had a heating element running through the middle. The tube was wound in a spiral underneath the pan. Unlike the earlier iron hotplate, the steel spiral was heated to red heat imparting more heat to the pan than the hotplate could [2]. The second technology is the glass-ceramic cooktops. In the 1970s, glass-ceramic cooktops started to appear. Electrical heating coils or infrared halogen lamps are used as heating elements. Because of it physical characteristics, the cooktop heats more quickly, less afterheat remains, and only the plate heats up while the adjacent surface remains cool [1]. A third technology is the induction cooking. This process has hitherto only heated ferromagnetic cookware directly through electromagnetic induction.

Revised Manuscript Received on November 25, 2020.

* Correspondence Author

Gyang Davou Chung*, Dept of Physics, Ahmadu Bello University Zaria, Nigeria. Email: gyangchung13@gmail.com

Pahalson C. A. D, Dept of Science, Plateau State Polytechnic BarkinLadi, Nigeria. Email: pahalson12@gmail.com

Jennifer Kadala, Dept of Physics, Ahmadu Bello University Zaria, Nigeria.

(c) The Authors. Published by Blue Eyes Intelligence Engineering and Sciences Publication (BEIESP). This is an open access article under the CC BY-NC-ND license (http://creativecommons.org/licenses/by-nc-nd/4.0/)
Present developments have enabled nonferrous cookware to work as well, but not as efficiently as ferrous. Induction stoves have a smooth glass-ceramic surface [3]. Thermal energy storage is the collection of heat energy in a medium or process for later use [4]. Heat storage, both seasonal and short term, is considered an important means for cheaply balancing high shares of variable renewable and nonrenewable electricity production. And also it integration in the electric and heating distributions in the energy system $[4,5,6]$. Thermal energy storage is achieved with greatly differing technologies that collectively accommodate a wide range of needs. Molten Salt technology uses the change in state of salt and it high thermal capacity to store heat. Hard Solids technologies: Concrete can be heated to a much higher temperature of about $1200{ }^{\circ} \mathrm{C}$ by e.g. electrical heating, coal etc. and because of it high density, has a high overall volumetric capacity of thermal energy storage [7]. It is the principle employed for heat storage in hot rocks, concrete, pebbles etc. Miscibility Gap Alloys technologies (MGA) rely on the phase change of a metallic material to store thermal energy. Electric Thermal Storage Heaters technologies consist of high-density ceramic bricks or feolite blocks heated to a high temperature with electricity, and may or may not have good insulation and controls to release heat over a number of hours [8] [9]. Ice-Based technology involved the production of ice during off-peak periods and used for cooling at later time. Cryogenic Energy Storage technology uses the liquification of air or nitrogen as an energy storage means [10]. Hot Silicon technology uses Solid or molten silicon which offers much higher storage temperatures than salts with consequent greater capacity and efficiency. Pumped-Heat Electricity Storage (PHES) technology; In a PHES, reversible heat-pump system is used to store energy as a temperature difference between two heat stores. Molecular Bonds and Salt Hydrate technology; uses endothermic or exothermic chemical reactions to store heat [4] [5] [6].

The technologies for thermal energy storage rely on the properties of the materials used i.e., on the Thermal Storage Materials (TSM). Generally, the Table 1 that follows gives the desired properties that a thermal process or material should have for effective thermal energy storage.

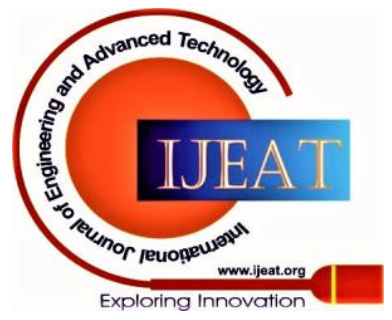




\section{Design and Implementation of Concrete Thermal Storage Stove}

Table 1: Characteristic of Thermal Storage Materials (TSMs) [2][7] [11] [12] [13]

\begin{tabular}{|c|c|}
\hline Desirable Characteristic & Explanation \\
\hline High chemical stability & $\begin{array}{l}\text { Chemically stable TSMs should handlea larger temperature swing and more } \\
\text { varied storage conditions. }\end{array}$ \\
\hline High energy storage density & $\begin{array}{l}\text { A high latent heat per unit volume allows more heat to be stored with less } \\
\text { material.This takes up less space. }\end{array}$ \\
\hline High thermal conductivity & A high thermal conductivity will allow for faster heat transfer. \\
\hline $\begin{array}{l}\text { The melting temperature should match the } \\
\text { use of the thermal storage system. }\end{array}$ & $\begin{array}{l}\text { TSMs have different melting temperatures. This allows them to be } \\
\text { customized to the particular heat load and heat source. }\end{array}$ \\
\hline $\begin{array}{l}\text { small change in volume during the phase } \\
\text { change }\end{array}$ & $\begin{array}{l}\text { Substances that change in volume during phase change must have } \\
\text { storage containers that can accommodate the volume change. }\end{array}$ \\
\hline Not flammable & $\begin{array}{l}\text { TSMs that are non-flammable are desirable since they do not pose a } \\
\text { potential hazard. }\end{array}$ \\
\hline Low cost & $\begin{array}{l}\text { Lower cost must be weighed with other characteristics, but a lower capital } \\
\text { cost will make the system more attractive. }\end{array}$ \\
\hline High availability & $\begin{array}{l}\text { Available substances are easy to obtain during the initial purchase and can } \\
\text { be replaced when necessary. }\end{array}$ \\
\hline Long life span & $\begin{array}{l}\text { Appropriate TSMs should show little to no degradation after high numbers } \\
\text { of melting cycles. }\end{array}$ \\
\hline Recyclability & $\begin{array}{l}\text { As TSMs do not last forever, it is important to consider if they can be } \\
\text { recycled when their lifetime has ended. }\end{array}$ \\
\hline Low corrosivity & $\begin{array}{l}\text { Non-corrosive TSMs are easier to store because they do not require special } \\
\text { storage containers or heat exchangers. }\end{array}$ \\
\hline No need for super cooling & $\begin{array}{l}\text { Ideally, TSMs should begin to store latent heat when their freezing } \\
\text { point is reached, without the need for super cooling. }\end{array}$ \\
\hline
\end{tabular}

\section{METHODOLOGY}

Electric energy is changeto thermal energy by the electric heating elements. The thermal energy created is store in the reinforce concrete. The stored thermal energy would be use for cooking in the absence of electric supply. In the absent of electricity, the stored thermal energy is thermally conducted through the rods within the reinforced concrete to the cooking point. In principle, concrete thermal storage technology is employed for this device.

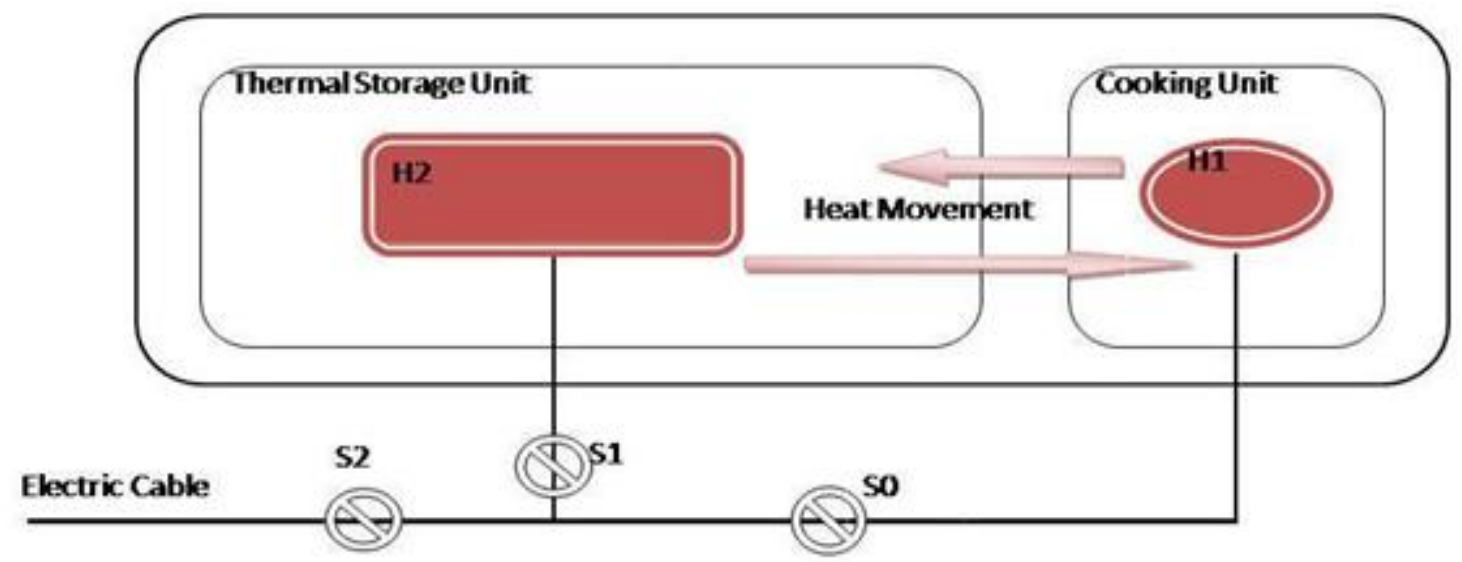

Fig. 1. The block diagram of device.

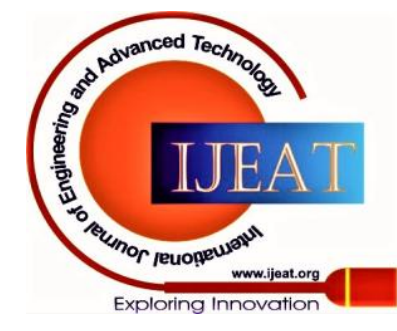


The device is made up two major units as indicated in the block diagram above. They are the thermal storage unit and the cooking unit. These units are merged together. Electricity flows to the two units through separates electric cables as indicated in the block diagram. Electric heating element(s) is included in each unit. When there is electric power supply, the direct cooking unit (cooking unit) heating element (H1) provide heat majorly for cooking and the remaining part of the heat flows to the thermal storage unit as indicated by the short arrow. Also, in the presence of electricity the heating elements $\mathrm{H} 2$ provide the heat to thermal storage unit for storing (thermal energy charging) for some amount of time until the storage unit is fully charged. When fully charged, switch S1 is set to off, so as to cut the power supply to the storage unit and to prevent excess heat from accumulating in the unit. When there is no power supply, stored heat from the thermal storage unit flows to the cooking unit for cooking as indicated by the longer arrow. For heat waste prevention, thermal cover is made to stop heat from flowing out of the device. Switch S2 is use to completely switch off power supply when it is fully charged and cooking is not taking place. Switch S0 is use to switch off power to the direct cooking unit when the device is charging and not in use.

The major parameter considered in this work is the total energy capacity of the device. The total thermal energy capacity of device is given by (1)

$$
\begin{gathered}
E=\left((1-\propto) V_{a s} \rho_{a} c_{a}+\propto V_{a s} \rho_{s} c_{s}+\rho_{r} V_{r} c_{r}\right)\left(T_{m}-\right. \\
T O \square \square \square \square(1)
\end{gathered}
$$

Where $\propto$ is a parameter that relate $V_{s}$ andV $V_{a} . \propto$ is a parameter that is obtain from the choice of the amount of aggregates relative to other materials in the reinforced concrete is given as;

$$
\square V_{s}=\propto V_{a s} \square \square \square \square \square V_{a}=(1-\propto) V_{a s}
$$
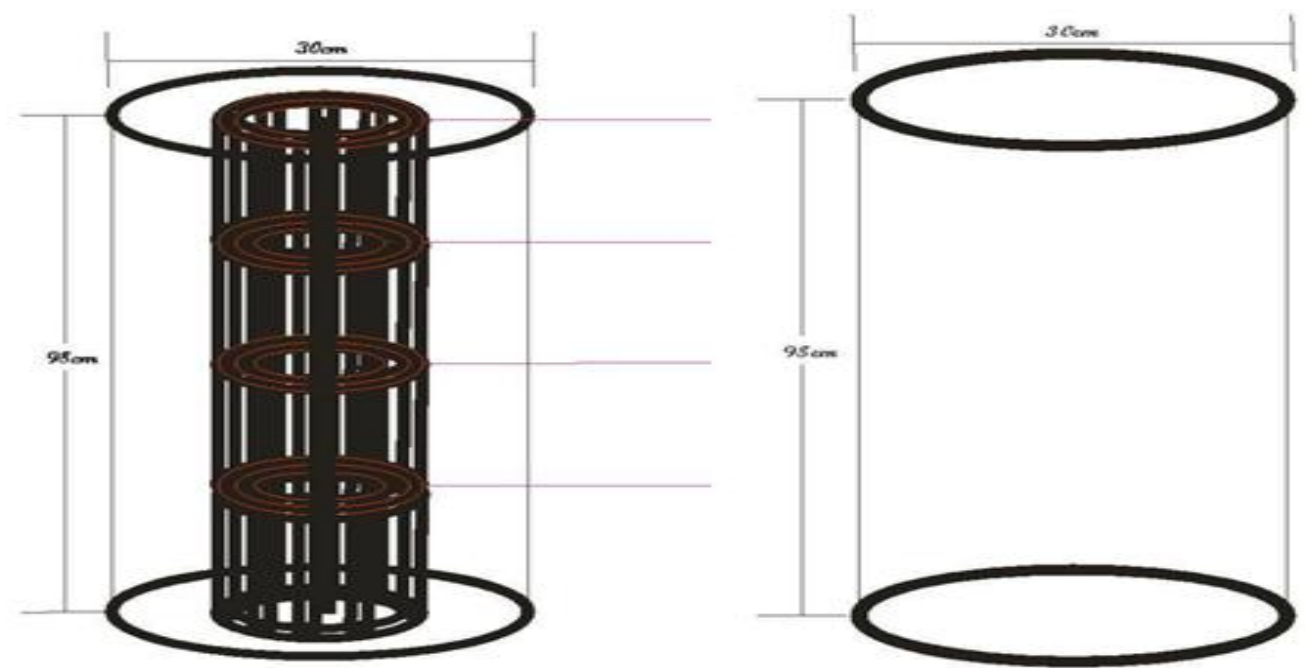

Fig. 2. Assemble electric heating elements and welded rods. Fig.3.Internal thermal storage unit.

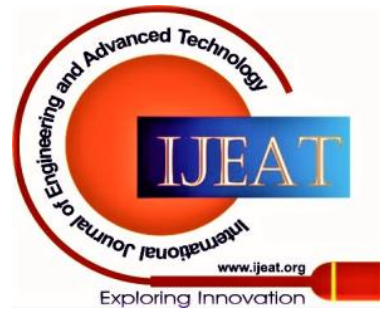




\section{Design and Implementation of Concrete Thermal Storage Stove}

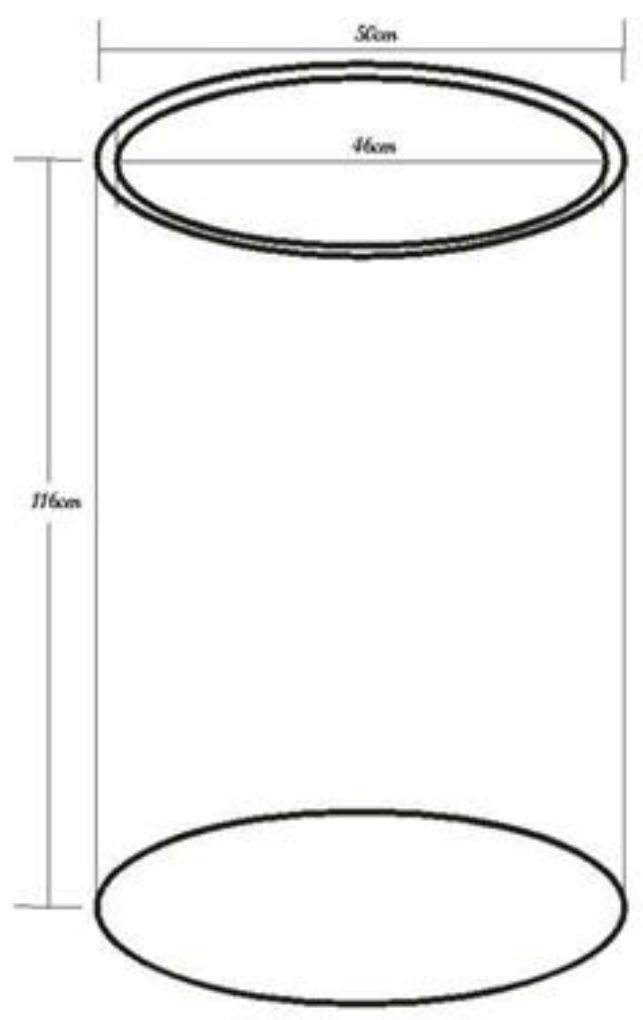

Fig. 4: The complete electric and thermalstorage stove. (External appearance)

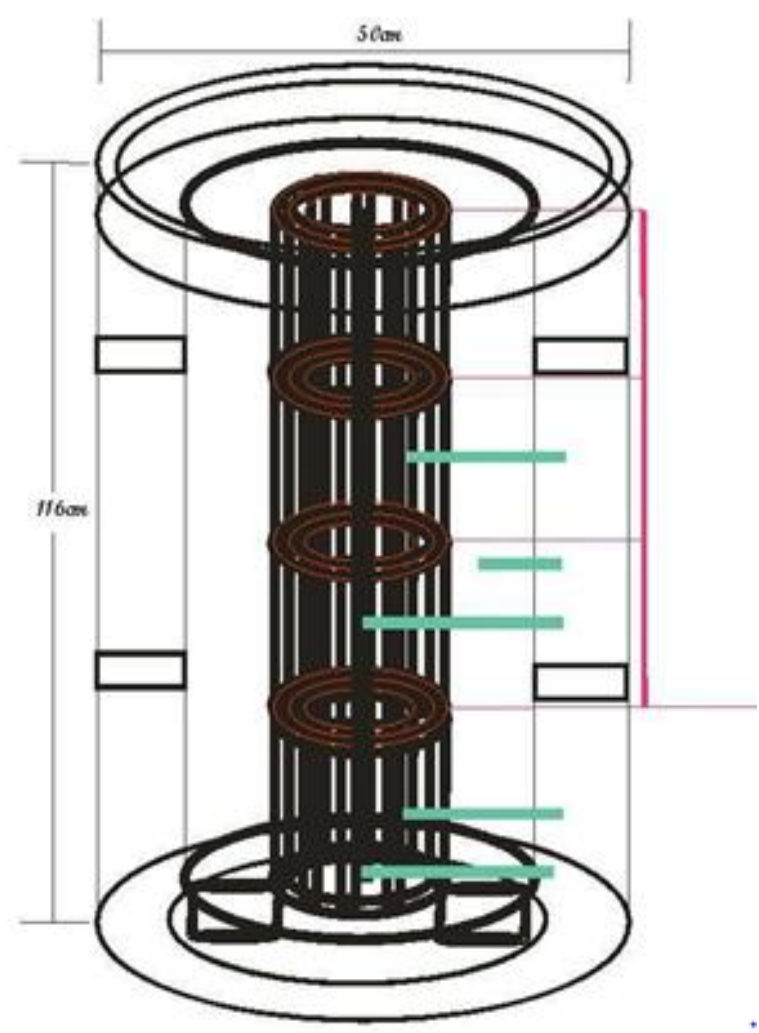

Fig. 5: Complete electric and thermal storage device. (Internal structure)
The green lines are rods for temperature measurements and red lines are electric cables for electric power flow to the heating elements.

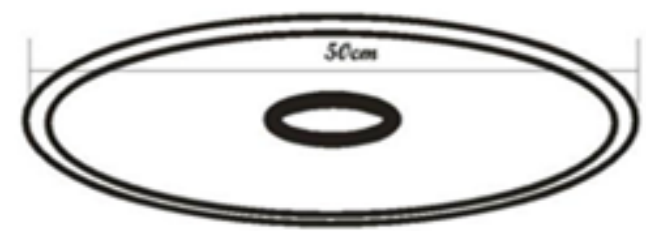

Fig. 6. Top cover of the electric and thermal storage stove. (External appearance)

\section{RESULTS AND DISCUSSION}

\section{A. Charging of Thermal Storage Unit of Stove}

In order to determine the charging behavior of the thermal storage unit, the stove was connected to the power source and was monitored for three hours (180 minutes). It was set under the following conditions;

Casted thermal storage unit was place in open environment for about 90 days (three months) to dry.

Ambient Temperature: $20 \pm 2{ }^{\circ} \mathrm{C}$

Average Alternating Voltage: $160 \pm 1 \mathrm{~V}$ (Was the average root mean square voltage available from the main during the measurement)

Switch S0 set to OFF and S1 set to ON. Since our interest was for the thermal storage unit only for this measurement.

The Stove was set to power and the thermometer reading at time intervals of 20 minute were obtained as in Table 1

Note: The thermometer was not in contact with the thermal storage unit rather in the gap between the thermal cover and the thermal storage unit. As a result of it position, the temperature obtained is not the temperature on the thermal storage unit but a value that is used to indicate the behavior of the storage unit. However, with certain correction to the measured temperature the actual values for the storage unit temperature can be obtained. This correction is expected to be unique for every device except if another technique other than this is use for the temperature measurement. Therefore, the temperature behaviors with time only give an approximate behavior of the thermal storage system. Other observations during measurements, Steam started coming out through an opening at the cooking section when the thermometer reads $67{ }^{\circ} \mathrm{C}$ and at about $70{ }^{\circ} \mathrm{C}$, a small amount of water was observed coming out at the bottom of the thermal cover. Both the steam and water increases slightly as the temperature increases with time.

From Table 1 and Fig. 7, the charging curve can be divided into three regions.

\section{B. Undercharged Region}

This is between $0{ }^{0} \mathrm{C}$ to $46{ }^{0} \mathrm{C}$ and was attained at about 80 minute of charging time. It can be observing on the graph that the rate of temperature increase is low compare to that in the charging region.

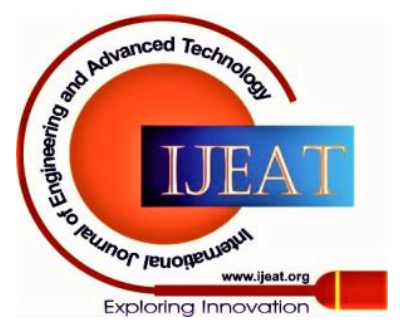


The device should not be discharged to this region because the device takes more time during charging in this region.

\section{Charging Region}

This is between $47{ }^{0} \mathrm{C}$ to $80{ }^{0} \mathrm{C}$ and the maximum temperature in this region was attained at about 140 minutes of charging time. This is the region that the device can be place to use. Also, the rate of increase in temperature in this region is high relative to the undercharged and charged (saturated) region.

\section{D.Charged (Saturated) region}

This is from $81{ }^{0} \mathrm{C}$ to any value above it. As seen from the graph, the rate of increase in temperature is almost stationary compares to that in the charging region. This region is also good for cooking. However, when the temperature reaches above $82{ }^{\circ} \mathrm{C}$, the thermal storage unit power should be switch off and allow the temperature to drop before switching it on again.

Note: This temperature range values are specific for this device due to the position of the thermometer which is unique. The temperature was obtained based on the position of the thermometer in the device during measurement. However, other devices when constructed will follow a similar charging curve and a slightly different temperature range.

\section{Table 1: Thermal stove charging data}

\begin{tabular}{|l|l|l|l|l|l|l|l|l|l|l|}
\hline Time \pm 1 minute & 0 & 20 & 40 & 60 & 80 & 100 & 120 & 140 & 160 & 180 \\
\hline Temperature $\pm 2^{\circ} \mathrm{C}$ & 22 & 24 & 30 & 36 & 46 & 62 & 74 & 80 & 82 & 84 \\
\hline
\end{tabular}

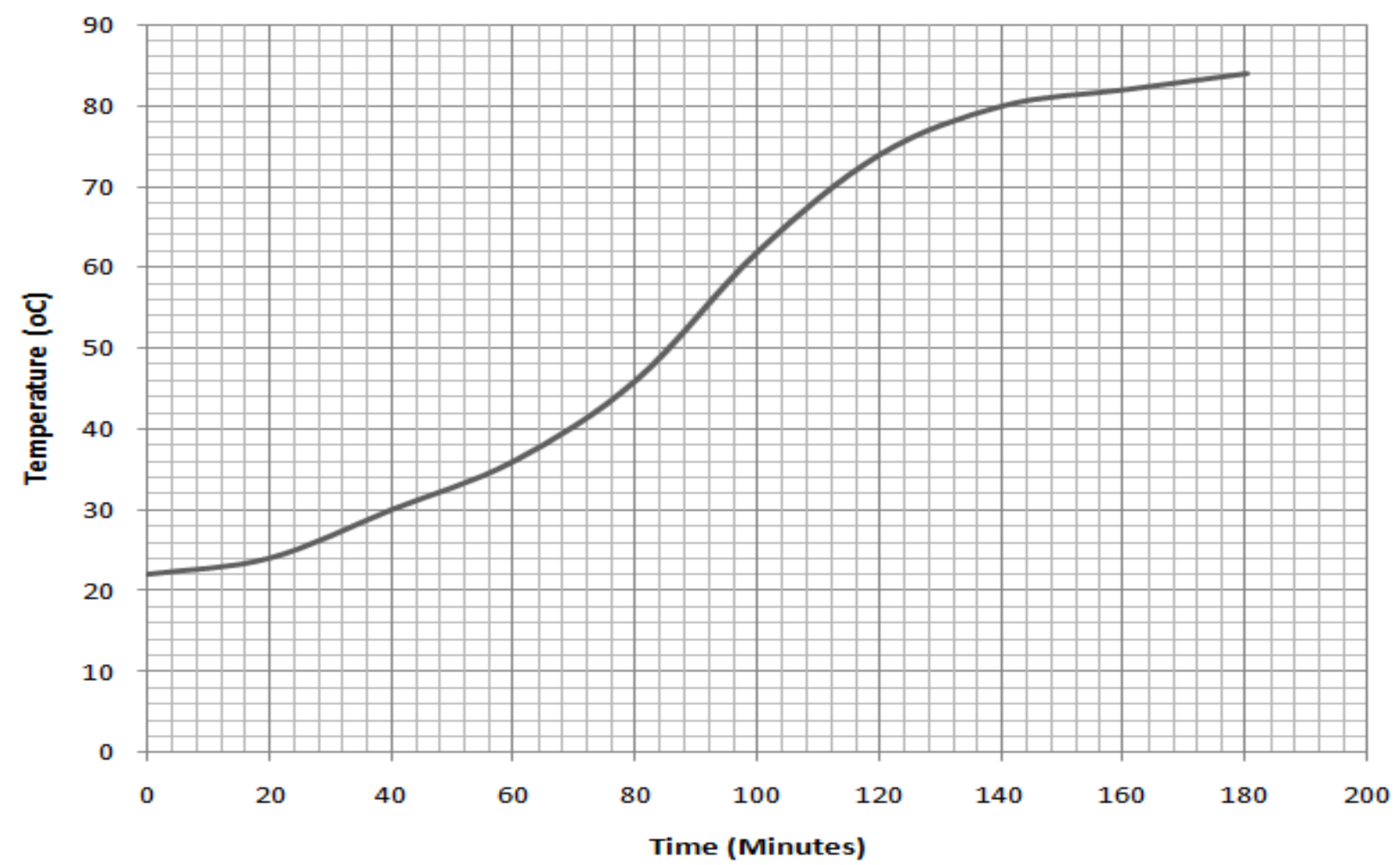

Fig. 7. Charging curve of thermal storage unit.

\section{E. Discharging of Thermal Storage Unit of Stove}

To know the heat discharge rate of the thermal storage stove, another temperature measurement was taken when the stove was charged $\left(84{ }^{0} \mathrm{C}\right)$ connected to the power source and monitored for seven hours and twenty minutes (440 minutes). It was set under the following conditions;

Casted thermal storage unit was place in open environment for about 90 days (three months) to dry i.e., under the same condition as that during the charging phase.

Ambient Temperature: $22 \pm 2{ }^{0} \mathrm{C}$

Switch S0 set to OFF and S1 set to OFF also. Since our interest was for the thermal storage unit heat retentive capability and thermal cover effectiveness to heat lost prevention. The Stove was switch off from power and the thermometer reading at time intervals of 20 minutes were obtained as given in Table 2 .

From Table 2 and Fig. 8 shows that the heat discharge rate is approximately linear for about seven hours. As observed, the temperature has been dropping by approximately $1{ }^{0} \mathrm{C}$. As observed, the major source of heat lost during experiment was convectional heat current. This happened because a vacuum was not created between the thermal storage unit and the thermal cover.

Published By:

Blue Eyes Intelligence Engineering and Sciences Publication

(C) Copyright: All rights reserved.

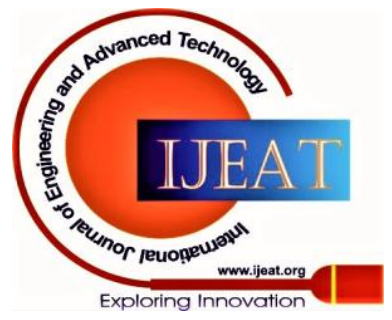




\section{Design and Implementation of Concrete Thermal Storage Stove}

If this temperature continues to drop linearly in this rate, then the device will reach the undercharged region in about 13 hours (approximately half a day). This shows that the device can only be very effective within 10 hours after charging.

Table 2: Thermal stove heat discharging data

\begin{tabular}{|l|l|l|l|l|l|l|l|l|l|l|l|l|}
\hline Time \pm 1 minute & 0 & 20 & 40 & 60 & 80 & 100 & 120 & 140 & 160 & 180 & 200 & 220 \\
\hline Temperature $\pm 2^{\circ} \mathrm{C}$ & 84 & 82 & 78 & 77 & 77 & 76 & 75 & 74 & 73 & 72 & 71 & 70 \\
\hline Time \pm 1 minute & 240 & 260 & 280 & 300 & 320 & 340 & 360 & 380 & 400 & 420 & 440 & \\
\hline Temperature $\pm 2^{\circ} \mathrm{C}$ & 69 & 68 & 66 & 65 & 64 & 63 & 62 & 61 & 60 & 58 & 58 & \\
\hline
\end{tabular}

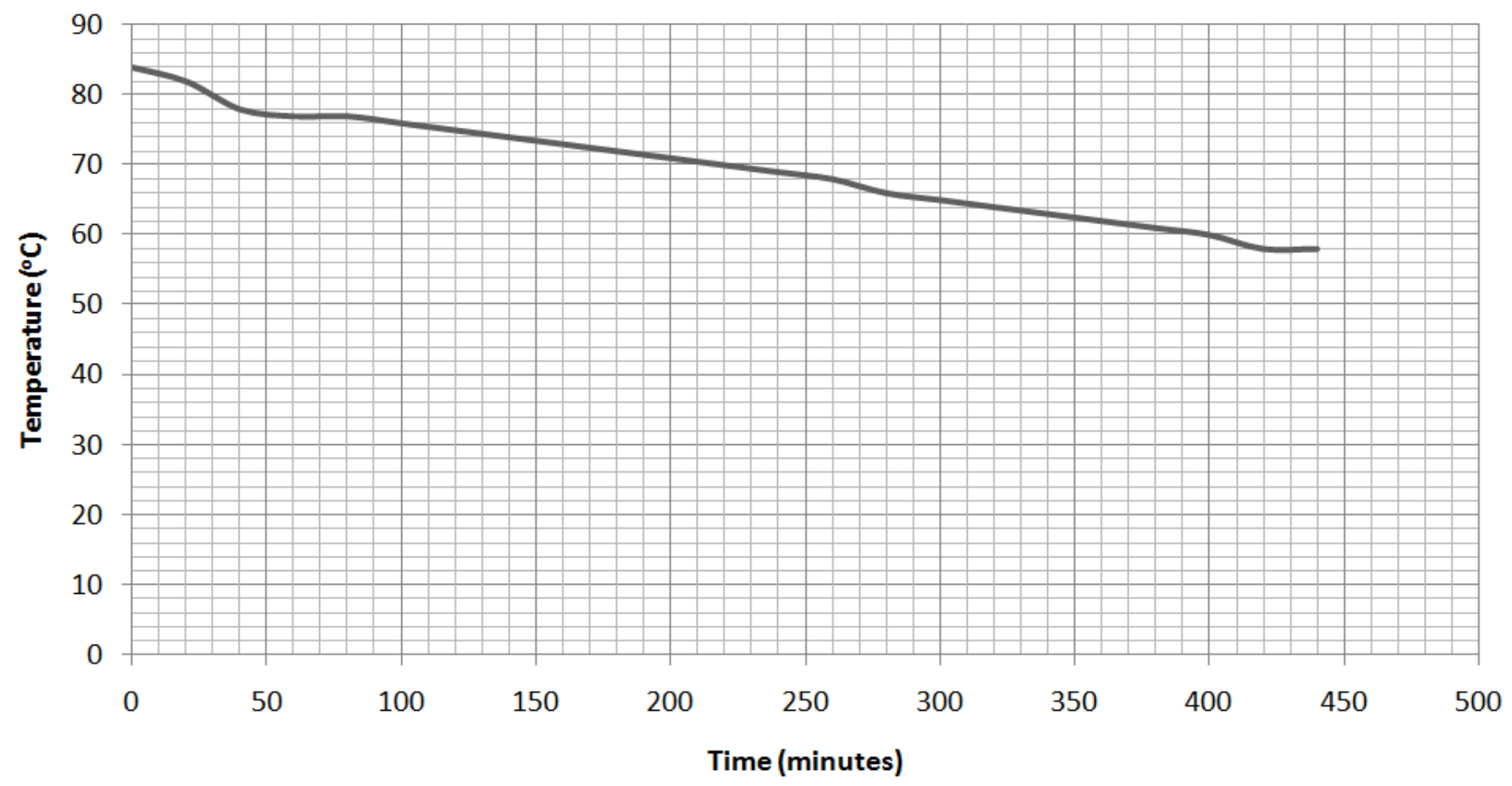

Fig.8: Heat discharging curve of thermal storage stove

\section{F. Cooking Using the Device}

From the charging and discharging graphs, it can be deducing that cooking would be more effective in the direct cooking unit in the presence of power compare to when the power was switched off. No measurement was carried out during the cooking test.

\section{CONCLUSION}

Man's continues need for a better and stable means of providing heat for cooking led to the construction of a thermal storage stove.

A thermal storage stove is a device that has the ability to store heat for cooking in later time in the presence or absence of electric power supply. The device uses electric heating elements to convert electric energy into heat energy. This converted heat is then stored in the thermal storage unit of the stove. The thermal storage unit is made up of reinforce concrete. The thermal storage unit is enclosed in a thermal cover.
The device was constructed and tested under certain conditions. Results obtained indicate that the device actually stored the heat.

In conclusion, a thermal storage stove with a theoretically estimated heat energy storage capacity of $2.7 \mathrm{MJ}$ was constructed. It is more effective in the first 10 hours when charged to about $82{ }^{0} \mathrm{C}$. It needs more improvement in the means of thermal heat conduction from the thermal storage unit to the cooking unit. Also, thermal heat lost means need improvement.

\section{RECOMMENDATIONS}

1. The radius to length ratio should be greater than 0.3061 to achieve stability and balance.

2. Mould should be made of light plank of about $0.4 \mathrm{~cm}$ in thickness. The size of aggregates should be monitored with the quantity of water in cement mixture. The device should be casted with the mould standing still.

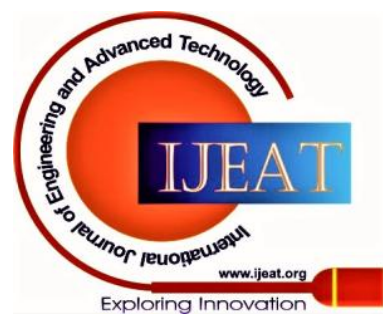


3. To reduce pores in the thermal storage unit, the aggregate and water mixture should be monitor. The mould should be properly and carefully fill with the mixture and allow it to settle gently.

4. A better finishing material like ceramic glass should be use for the stove cooking surface.

5. To reduce excess heat lost, a better thermal cover technology should be use. Also, a cylindrical shape external cover should be use. The cylindrical shape has the ability to distribute heat to different position almost equally in all direction

\section{REFERENCE}

1. Electric Stove" Retrieved on $28^{\text {th }}$ July 2017; https://en.wikipedia.org/wiki/Electric stove

2. Ahme, t A., (2007). "Manufacturing Properties of Engineering Materials" Lecture Notes ITU Dept. of Mechanical Engineering

3. Kanthal, S., (1999) "Electric Heating Element Handbook" Edited byTexterTryek, AB Hallstahammar Sweden, PRIMAtryck, Hallstahammar

4. Stevens V, Craven C, Grunau, B. (2013). "Thermal Storage Technology Assessment" Cold Climate Research Center

5. Aberg P. K, Dronninglund F. D, Johan F. (2015). "Construction of Heat Storage" GSE Environmental

6. Mangold, D., Schmidt, T. (2007) "The next Generations of Seasonal Thermal Energy Storage in Germany" Solites - Steinbeis Research Institute for Solar and Sustainable Thermal Energy Systems Stuttgart, Germany

7. Kuznetsov I.V, Yekaterinburg "Fundamentals of Stove Construction" available in www.stove.da.ru

8. Concrete" Retrieved on $28^{\text {th }} \quad$ July 2017 https://en.wikipedia.org/wiki/Concrete

9. Fenghong F., (2015). "Mechanical and Thermal Properties of Fly Ash-Based Geopolymer Cement" MSc. Thesis, Agricultural and Mechanical College Louisiana State University.

10. Nelkon M, Parker P. (1995). "Advanced Level Physics" 7th Edition, CBS Publishers \& Distributors Pvt. Ltd

11. List of Materials Properties" Retrieved on $28^{\text {th }}$ July 2017 https://en.wikipedia.org/wiki/List of materials properties

12. "What-is-Cast-Iron-its-Process-Properties-and-Applications"
Retrieved
$28^{\text {th }}$
July

https://www.slideshare.net/Searchnscore/what-is-cast-iron-itsprocess-properties-and-applications

13. Adegbola A.A., Adogbeji O.V., Abiodun O.I., Olaoluwa, S. (2012). "Design, Construction and Performance Evaluation of Low Cost Electric Baking Oven" Innovative Systems Design and Engineering Vol 3, No.11

\section{AUTHOR PROFILE}

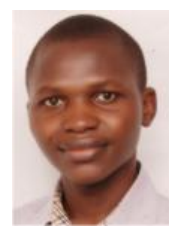

Gyang Davou Chung. Obtained B.Tech. Applied Physics from Abubakar Tafawa Balewa University Bauchi, Nigeria. Where he did a research work on the 'Impact of Six Potential Wells in Inertial Electrostatic Confinement Fusion. And at present, he is undertaking an M.Sc. in Nuclear Physics at Ahmadu Bello University Zaria, Nigeria doing research on the Nuclear Structure of Argon and Potassium. He is also innovative i.e he looks within his community and design devices and implement the designs to solve problems he observed. His research interest is on Nuclear Structure, Security and Energy Systems. He is a member of World Institute for Nuclear Security (WINS); a Certified Nuclear Security Professional (CNSP) by WINS and a member of Institute of Nuclear Materials Management (INMM) ABU Student chapter.

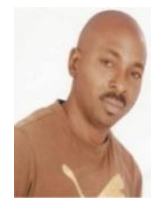

Pahalson C. A. Dreceived his M.Eng degree inCommunicationsEngineering from Federal University of Agriculture Makurdi, Benue State, Nigeria. He is a member of the Nigeria Society of Engineers (NSE)and a member of Institute of Physics (MNIP). Hisof current research interest is on Radio Propagation for mobile communications, GSM Technology, Signal Analysis, Wireless Communications and Networks, Spectrum Sensing and Cognitive Radio Networks.He is currently working as a Senior lecturer in the Department of Science, Plateau State Polytechnic BarkinLadi Jos, Nigeria.

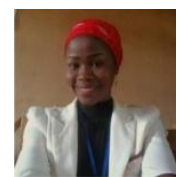

Jennifer Kadala: Obtained B.Sc. Physics from University of Maiduguri, Nigeria and at present doing her M.Sc. in Radiation Biophysics at Ahmadu Bello University Zaria, Nigeria. One of her motivation in radiation studies is seeking the possible contribution of radiation to tooth coloration of some of the indigenous people of Maiduguri in Nigeria. She teaches for a period of two years after her undergraduate studies. Her area of research interest is on the effects of radiations on humans and seeking the best possible means to communicate them to those in the rural community on time before damages are made.

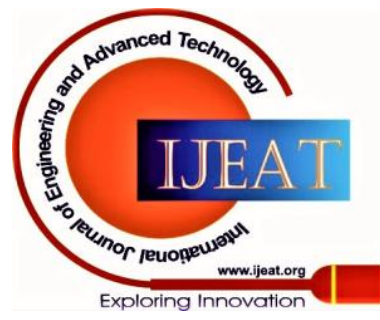

